\title{
Using Some Application Programs in VRF Air-Conditioning System Design
}

\author{
Duraid M. Al-Najjar \\ Licentiate Engineer, Iraqi Engineers Union, Al-Mansour - Baghdad - Iraq
}

\begin{abstract}
Computer Application Programs is developed to aid us in order to solve many problems in several sectors such as engineering, medicine, education, military, science, etc. Using Application Programs enables us to design, control, monitor and implement many tasks and projects easier, faster and more accurate. In this paper, we used three of application programs, two of them are well-known for us AutoCAD 2010 and Microsoft Excel 2010, where the third program is Midea Selection Software to design a VRF Air-conditioning System, and we chose a project of Villa which consisted of several rooms, this project were used to apply these programs in its VRF System Design. The AutoCAD program was used to calculate the area of each room in the project, where the Excel program was used to find out the rooms' needs of Air-conditioning, while the Selection Software was used to select the outdoor and indoor units for the project.
\end{abstract}

Keywords: Application Programs, VRF Air-conditioning System, Selection Software

\section{Introduction}

Computer software, or simply software, is a part of a computer system that consists of data or computer instructions, in contrast to the physical hardware from which the system is built. In computer science and software engineering, computer software is all information processed by computer systems, programs and data. Computer software includes computer programs, libraries and related non-executable data, such as online documentation or digital media. Computer hardware and software require each other and neither can be realistically used on its own [1]

Using programs enables us to design, control, monitor and implement many tasks and projects easier, faster and more accurate. A computer program is a collection of instructions that performs a specific task when executed by a computer. A computer requires programs to function and typically executes the program's instructions in a central processing unit [2].

A computer program is usually written by a computer programmer in a programming language. From the program in its human-readable form of source code, a compiler can derive machine code - a form consisting of instructions that the computer can directly execute. Alternatively, a computer program may be executed with the aid of an interpreter[1].

A part of a computer program that performs a well-defined task is known as an algorithm. A collection of computer programs, libraries, and related data are referred to as software. Computer programs may be categorized along functional lines, such as application software or system software [3].

An application program (app or application for short) is a computer program designed to perform a group of coordinated functions, tasks, or activities for the benefit of the user. Examples of an application include a word processor, a spreadsheet, an accounting application, a web browser, a media player, an aeronautical flight simulator, a console game or a photo editor. The collective noun application software refers to all applications collectively.
This contrasts with system software, which is mainly involved with running the computer.

Applications may be bundled with the computer and its system software or published separately, and may be coded as proprietary, open-source or university projects. Apps built for mobile platforms are called mobile apps[4].

There are many types of application software [5]:

- Operating System Programs: Such as Windows, MacOS, and Linux

- Words Processing: Such as Microsoft Word, LibreOffice and iWork

- Spreadsheets Programs: Such as Microsoft Excel.

- Database Programs: Such as Microsoft Access.

- Educational Software Programs: Drill \& Practice Mode and Simulation Mode

- Photo Processing Programs: Such as Photoshop and Photo Express.

- Video and Audio Programs: Such as Video Express and Real Player

- Web Browser Programs: Such as Mozilla Firefox and Google Chrome

- Engineering Programs: Such as AutoCAD, Primavera and SAB.

- Security and Antivirus Programs: Such as Norton and Kaspersky.

- Entertainment Software Programs: Such as video games, and screen savers

\section{Programs}

In our study, we'll use three of application software:

\subsection{AutoCAD 2010}

AutoCAD is a commercial Computer-Aided Design (CAD) and drafting software application. Developed and marketed by Autodesk, AutoCAD was first released in December 1982 as a desktop app running on microcomputers with internal graphics controllers. Prior to the introduction of AutoCAD, most commercial CAD programs ran on mainframe computers or minicomputers, with each CAD 


\section{International Journal of Science and Research (IJSR) \\ ISSN (Online): 2319-7064}

Index Copernicus Value (2016): 79.57 | Impact Factor (2015): 6.391

operator (user) working at a separate graphics terminal. Since 2010, AutoCAD was released as a mobile- and web app as well, marketed as AutoCAD 360.

AutoCAD is used across a wide range of industries, by architects, project managers, engineers, graphic designers, and many other professionals.

AutoCAD was derived from a program begun in 1977 and released in 1979 called Interact CAD, also referred to in early Autodesk documents as MicroCAD, which was written prior to Autodesk's (then Marinchip Software Partners) formation by Autodesk cofounder Mike Riddle.

The first version by Autodesk was demonstrated at the 1982 Comdex and released that December. As Autodesk's flagship product, by March 1986 AutoCAD had become the most ubiquitous CAD program worldwide. The 2018 release marked the 32nd major release of AutoCAD for Windows. The 2014 release marked the fourth consecutive year of AutoCAD for Mac[6].

\subsection{Microsoft Excel 2010}

Microsoft Excel is a spreadsheet program developed by Microsoft for Windows, macOS, Android and iOS. It features calculation, graphing tools, pivot tables, and a macro programming language called Visual Basic for Applications. It has been a very widely applied spreadsheet for these platforms, especially since version 5 in 1993. Excel forms part of Microsoft Office [7].

Microsoft Excel has the basic features of all spreadsheets, using a grid of cells arranged in numbered rows and letternamed columns to organize data manipulations like arithmetic operations. It has a battery of supplied functions to answer statistical, engineering and financial needs. In addition, it can display data as line graphs, histograms and charts, and with a very limited three-dimensional graphical display. It allows sectioning of data to view its dependencies on various factors for different perspectives (using pivot tables and the scenario manager). It has a programming aspect, Visual Basic for Applications, allowing the user to employ a wide variety of numerical methods, for example, for solving differential equations of mathematical physics, and then reporting the results back to the spreadsheet [8]. It also has a variety of interactive features allowing user interfaces that can completely hide the spreadsheet from the user, so the spreadsheet presents itself as a so-called application, or decision support system (DSS), via a customdesigned user interface, for example, a stock analyzer, or in general, as a design tool that asks the user questions and provides answers and reports. In a more elaborate realization, an Excel application can automatically poll external databases and measuring instruments using an update schedule, analyze the results, make a Word report or PowerPoint slide show, and e-mail these presentations on a regular basis to a list of participants. Excel was not designed to be used as a database [9].

\subsection{Midea VRF Selection Software}

The VRF Selection Software of Midea is an application program developed by Midea Company with (11) different language used to design VRF Air-Conditioning System for any project.

After enter to the program, the software demand a name for your project, the location of the project (As the city location is very important factor because of the difference in the temp. degree), then we start designing our project. We must give the software number of floors, rooms, and then start select our Outdoor and Indoor, finally the program will give us a final report for our project.

\section{Air-Conditioning Systems}

Air-conditioning Systems can be simply defined by an electrical - mechanical system used for cooling and drying the air in a building, room, etc. till it reaches the required temperature degree. There are various types of air conditioners like window air conditioner, split air conditioner, packaged air conditioner and central air conditioning system.

Generally, we can classify Air-conditioning Systems depending on their usage:

- Home appliances: used in homes, such as Window type and Split Units.

- Package Units: used in Halls, stores.

- VRF System: used in many rooms project such as hotel and institutions.

- Chiller System: used in large - open place such as airport, large hospital.

Variable Refrigerant Flow (VRF), also known as Variable Refrigerant Volume (VRV), is an HVAC technology invented in Japan by Daikin company in 1982. Like ductless mini-splits VRFs use refrigerant as the cooling and heating medium. This refrigerant is conditioned by a single outdoor condensing unit, and is circulated within the building to multiple fan-coil units (FCUs).

VRFs are typically installed with an Air conditioner inverter which adds a DC inverter to the compressor in order to support variable motor speed and thus variable refrigerant flow rather than simply perform on/off operation. By operating at varying speeds, VRF units work only at the needed rate allowing for substantial energy savings at partial-load conditions.

In this paper, we focused on VRF system because of its advantages, we used VRF system in order to reduce the power consumed, as this system operates according to the number of operated indoor units not the number of total indoor units. Also this system used Pipes instead of Ducts, and that gives us more simplicity and less cost, the other point is the wide range of indoor units that gives us more flexibility [10]. 


\section{International Journal of Science and Research (IJSR) \\ ISSN (Online): 2319-7064 \\ Index Copernicus Value (2016): 79.57 | Impact Factor (2015): 6.391}

\section{Practical Steps}

\subsection{First Step}

We start drawing our project with AutoCAD program, where before that we must have the dimensions of each room in the project. In this study, we'll take a sample of project that need to be air-conditioned.

So, we begin to calculate the area of each room so as to evaluate later their needs of Air-conditioning.

The area can be calculated using equations of Area, but sometimes the rooms / halls may have irregular shape, and that's forces us to use AutoCAD program to find out its area. There're two methods to find the area using AutoCAD:

- Draw the room by using Polyline command, then right click on it and choose Properties, then find Area.

- The other method is by using Hatch command to fill the closed area, hen right click on it and choose Properties, then find Area.

Then we apply the above step to the other rooms. After finish calculating the area of all rooms, we start the Second step.
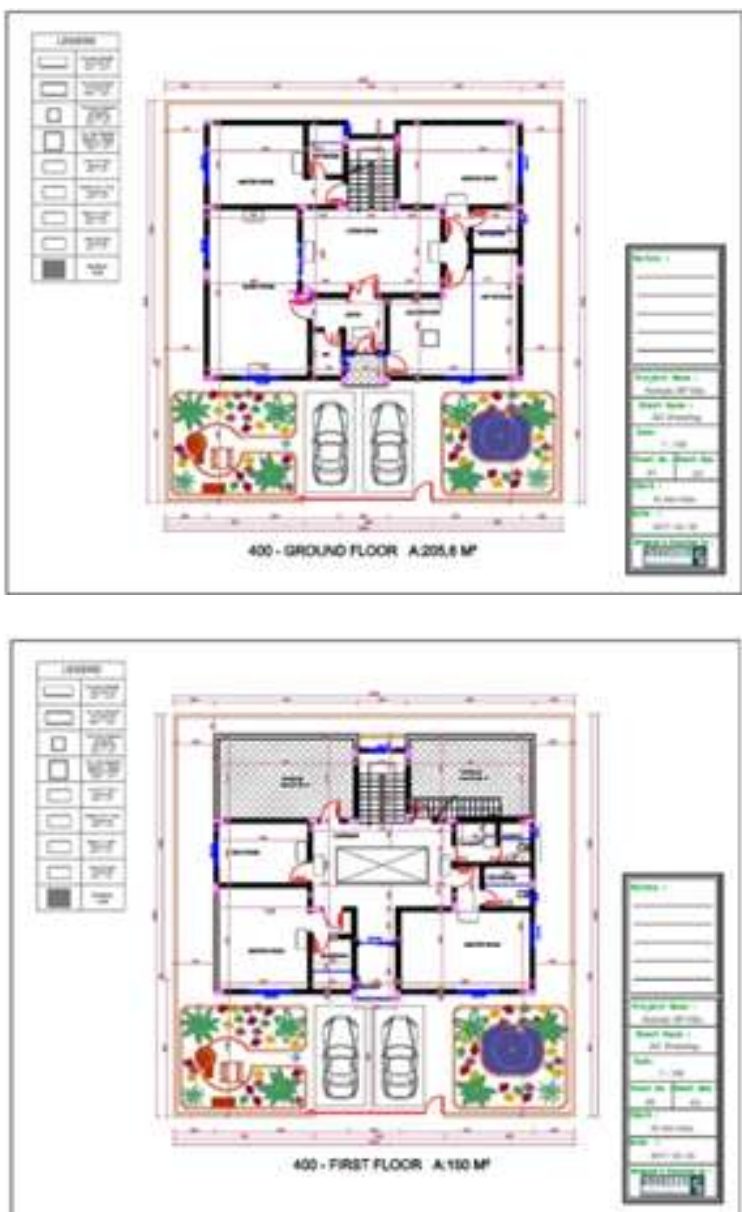

Figure 1: The AutoCAD Drawings of Villa Project

\subsection{The Second Step}

We start working on Excel Program in order to calculate the needs of Air-conditioning.
In the start, we must group the project into groups depending on the number of floors, then sub-group into number of rooms in each floor.

The fourth column represents the name of each room, then the area of the room (from the previous step), after that we choose the cooling capacity in $\left(\mathrm{Kw} / \mathrm{m}^{2}\right)$, usually we choose $0.3 \mathrm{Kw}$ for each squared meter for $3 \mathrm{~m}$ height, this value depends on the height of the room, but many other factors also effect on this quantity, such as its contents, locations, wall and ceiling, and others. Where if the room has heat source, if the room has many persons, if the door always opened, or if the height is greater than $3 \mathrm{~m} \ldots$ all that effect on that value and forces us to increase the value. For example, if the room is a restaurant with height $3.5 \mathrm{~m}$, we must take $0.35 \mathrm{Kw}$ or even $0.4 \mathrm{Kw}$.

As a result, we found the total needs of A.C.

Table 1: The Calculation Table using Microsoft Excel

\begin{tabular}{|c|c|c|c|c|c|c|c|c|}
\hline \multicolumn{9}{|c|}{ - $3^{2} \quad 4$} \\
\hline 4 & A & B & C & D & E & F & Q & H \\
\hline 1 & \multicolumn{6}{|c|}{ Krabala Villa VRF System } & & \\
\hline 3 & Hent & Floor & $\begin{array}{l}\text { rroom } \\
\text { Neme }\end{array}$ & Nea $(m$ ) & $\begin{array}{l}\text { Cosing } \\
\text { Capechy } \\
\text { (Rumin2) }\end{array}$ & $\begin{array}{l}\text { Tois } \\
\text { Ceoing } \\
\text { Power (kw) }\end{array}$ & & \\
\hline 4 & 1 & \multirow{6}{*}{ G:F. } & MRI & 218 & 03 & 6.54 & & \\
\hline 3 & 2 & & MRZ & 29 & 03 & 78 & & \\
\hline 6 & 3 & & LA & 31 & 03 & 9.3 & & \\
\hline 7 & 4. & & Gh & 393 & 03 & 11.79 & & \\
\hline 8 & 5. & & Kteren & 185 & Q3. & 5.55 & & \\
\hline 9 & 6 & & Entry & 78 & 03 & 2.34 & & \\
\hline 10 & 7 & \multirow{4}{*}{$F, F$} & M.R3 & 258 & 03 & 765 & & \\
\hline 11 & 0 & & MR 4 & 20 & 03 & 0.4 & & \\
\hline 12 & 9 & & Comser & 328 & 0.3 & 9.84 & & \\
\hline 19 & 10 & & Maid & 138 & 03 & 405 & & \\
\hline 14 & & & & & KW & 73.26 & & \\
\hline 15 & & & & & Tons & 20.84 & & \\
\hline 16 & & & & & & & & \\
\hline
\end{tabular}

\subsection{The third step}

The third step is using Midea VRF Selection Software

The VRF Selection Software of Midea gives us a wide range of selection model:

- Indoor Units: There are many types to be selected, such as Cassette, Duct and wall mounted type, etc.

- Outdoor unit depends on the total capacity of indoor units, the group of an outdoor units may reach to 70 Tons. This value is preferred to be $90 \%-110 \%$.

- Also the software gives us the ability to draw the piping of the project system and all its needs of branches.

- Finally, the software gives us a report with a list of all system materials and details. 


\section{International Journal of Science and Research (IJSR) \\ ISSN (Online): 2319-7064}

Index Copernicus Value (2016): 79.57 | Impact Factor (2015): 6.391

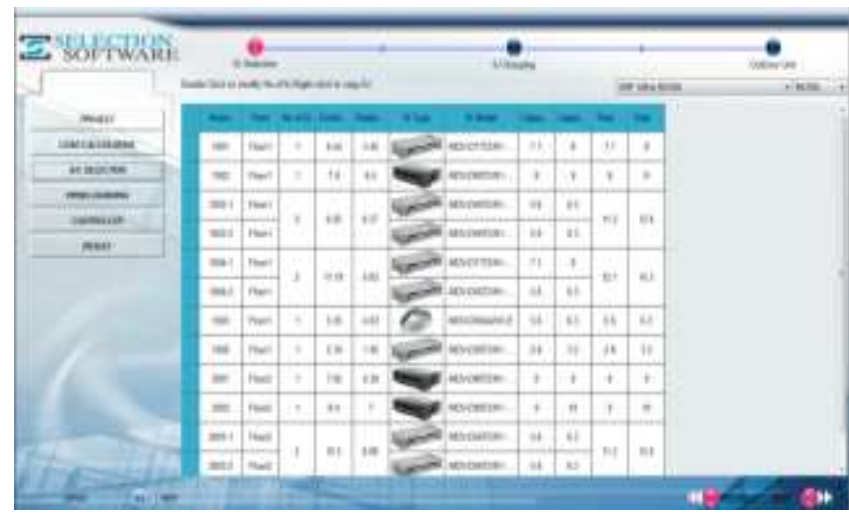

Figure 2: The Selection of Indoor Units in Midea Selection Software

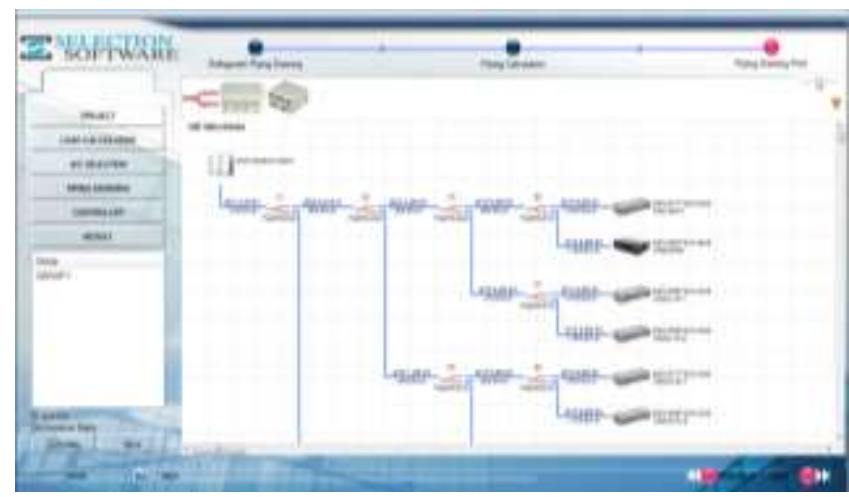

Figure 3: The Piping Drawing in Midea Selection Software

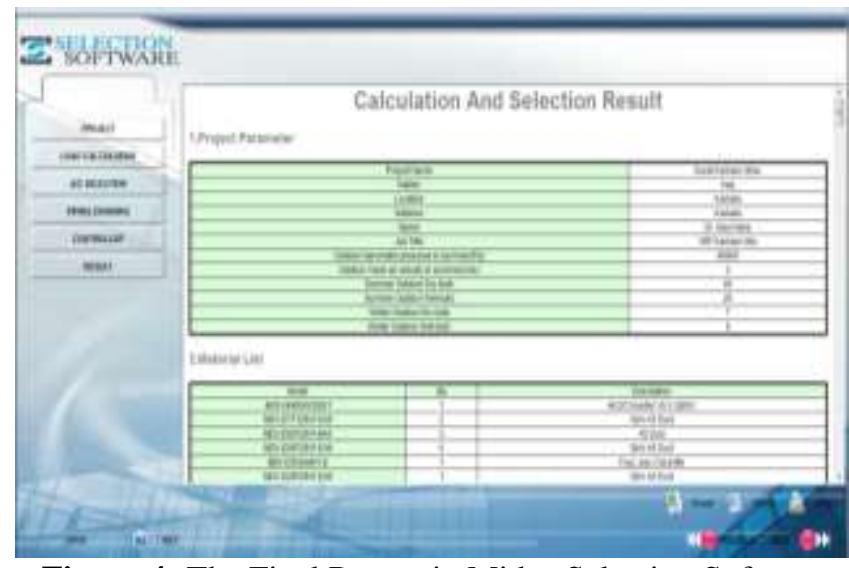

Figure 4: The Final Report in Midea Selection Software

\section{Conclusion}

We concluded that the application programs helped us to solve our practical problems to design a VRF AirConditioning System in simple, quick and precise way, while the traditional method take too long time to be finished in the same accuracy.

\section{References}

[1] Campbell-Kelly, Martin; Aspray, William (1996). Computer: A History of the Information Machine. New York: Basic Books. ISBN0-465-02990-6.

[2] Austerlitz, Howard (2003). Data acquisition techniques using PCs (2nd ed.). Academic Press. p. 281 ff. ISBN 0-12-068377-6.
[3] Ryan, Thorne (2013). "Caffeine and computer screens: student programmers endure weekend long appathon". The Arbiter. Retrieved 2015-10-12.

[4] Rochkind, Marc J. (2004). Advanced Unix Programming, Second Edition. Addison-Wesley. p. 1.1.2.

[5] Silberschatz, Abraham (1994). Operating System Concepts, Fourth Edition. Addison-Wesley. p. 59. ISBN 0-201-50480-4.

[6] Yare, Evan (2012). "AutoCAD's Ancestor". 3D CAD World. Retrieved 24 January 2014.

[7] Harnett, Donald L. \&Horrell, James F. (1998). Data, statistics, and decision models with Excel. Wiley. ISBN 0-471-13398-1.

[8] Şeref, Michelle M. H. \&Ahuja, Ravindra K. (2008). "A portfolio management and optimization spreadsheet DSS". Handbook on Decision Support Systems 1: Basic Themes. Springer. ISBN 3-540-48712-3.

[9] Bourg, David M. (2006). Excel scientific and engineering cookbook. O'Reilly. ISBN 0-596-00879-1.

[10] Thornton, Brian (2012). Variable Refrigerant Flow Systems. General Services Administration (Report). US Federal Government. Retrieved 2013-08-06.

\section{Author Profile}

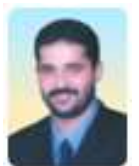

Duraid M. Al-Najjar received the B.Sc. in Computer Engineering from University of Baghdad in 2000. During 2001 - 2004, he worked in Computer and Programming Bureau, after that he worked in Amarseen Company for Engineering Services. He now the Manager of Design and Engineering Department in that company. 